\title{
Avaliação de processos de misturas de concretos com agregados graúdos reciclados
}

\author{
Influence of the mixing processes in concrete with \\ aggregates coarse recycled concrete
}

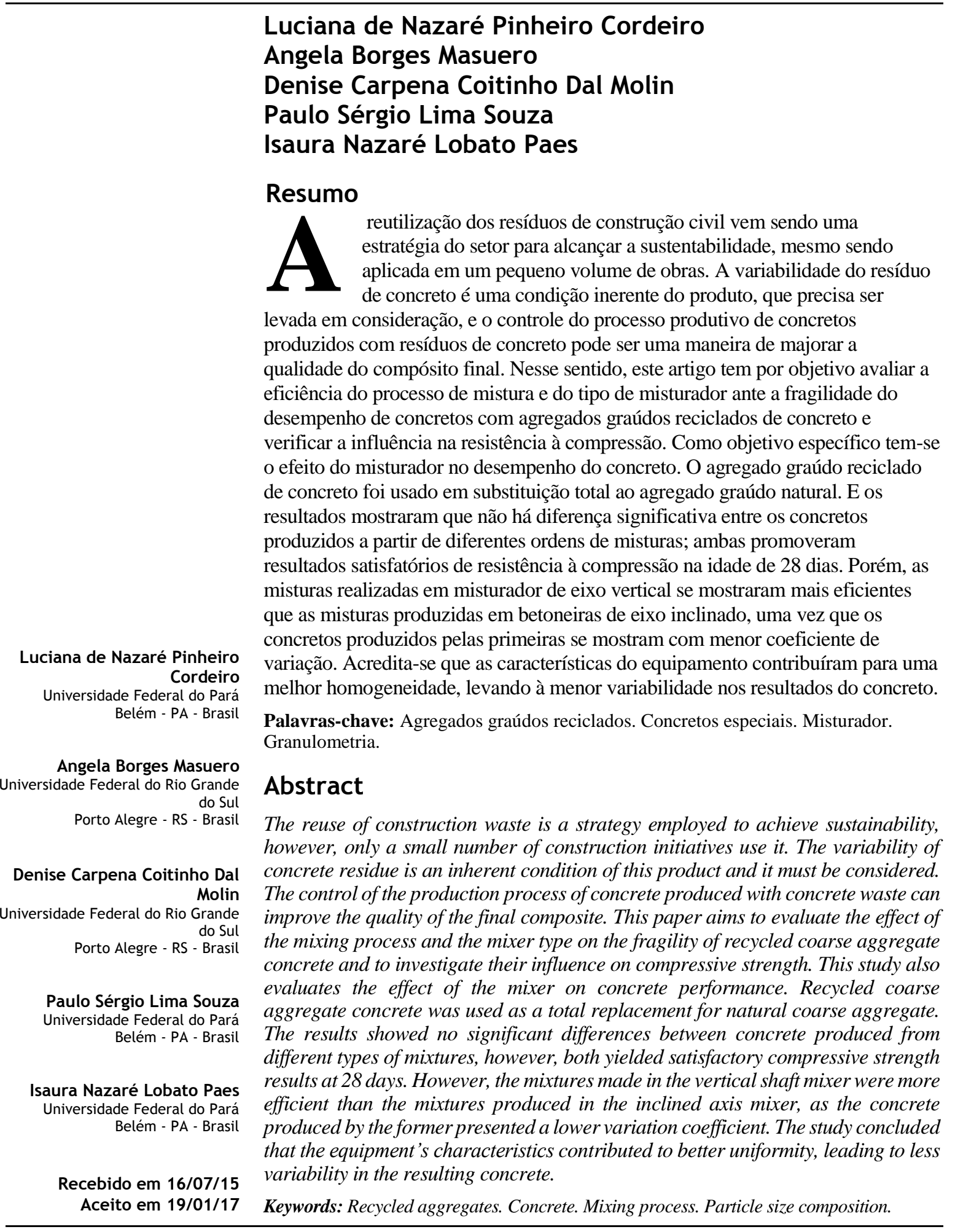

CORDEIRO, L. de N. P.; MASUERO, A. B.; DAL MOLIN, D. C. C.; SOUZA, P. S. L.; PAES, I. N. L. Avaliação de processos de misturas de concretos com agregados graúdos reciclados. Ambiente Construído, Porto Alegre, v. 17, n. 3, p. 255-265, jul./set. 2017. ISSN 1678-8621 Associação Nacional de Tecnologia do Ambiente Construído. http://dx.doi.org/10.1590/s1678-86212017000300174 


\section{Introdução}

O conceito de desenvolvimento sustentável está cada vez mais inserido no âmbito da construção civil. Esse setor, caracterizado por consumir e descartar grande volume de materiais, vem assumindo práticas que visam à concepção de uma construção mais sustentável, tais como o reúso de água nos canteiros, a utilização de materiais ecoeficientes, a redução do consumo de energias e o reaproveitamento de resíduos de construção e demolição.

A condição ideal seria não gerar os resíduos, contudo essa ainda não é uma realidade possível.

$\mathrm{O}$ resíduo de construção e demolição representa a maior fração, em massa, dos resíduos sólidos urbanos gerados no mundo (RAO; JHA; MISRA, 2007; ASSOCIAÇÃO..., 2011; JACOBI; BESEN, 2011). Além dos rejeitos de demolições de estruturas de concreto, consideram-se como resíduos de construção civil os restos de argamassas, blocos, tijolos e resíduos de fábricas de pré-moldados (BUTTLER, 2003). Diante dessas problemáticas, é preciso tomar iniciativas que promovam a destinação adequada desses entulhos, uma vez que os centros urbanos não têm áreas suficientes para a deposição final desse material.

Brito Filho (1999) considera os materiais gerados e descartados pelas obras de construção civil verdadeiras jazidas de matérias-primas a serem exploradas. Diversos estudos mostram que o agregado reciclado pode ser utilizado em concretos, argamassas, pré-moldados, entre outros (LEITE, 2001; CABRAL, 2007; LOVATO, 2007). Contudo, a falta de padronização com relação à caracterização do material (LEITE, 2001; ANGULO, 2005; ULSEN, 2011) e a falta de parâmetros de controle de produção (CORDEIRO, 2013) impedem sua utilização de forma disseminada.

Segundo Leite (2001), o agregado reciclado apresenta características intrínsecas que afetam o desempenho dos concretos com ele produzidos. $\mathrm{O}$ formato irregular desse material, a menor massa específica e a maior porosidade influenciam diretamente nas propriedades dos concretos tanto no estado fresco, quanto no endurecido. Nesse sentido, diversos autores vêm desenvolvendo estudos, principalmente em agregados reciclados de concreto, na tentativa de suprir e/ou minimizar os efeitos negativos decorrentes das características desse material, utilizando para isso tratamentos mecânicos, térmicos e químicos, que demandam muitas vezes custo e tempo, mas que levam a resultados satisfatórios (KATZ, 2003; MÜLLER; LINSZ, 2004; MOHAMED et al., 2012). A escolha do processo de beneficiamento pode também ser uma alternativa para se obterem agregados reciclados com características apropriadas. Gomes et al. (2015) demonstraram que a fragmentação de agregados por diferentes processos reduz a porosidade do material e, muitas vezes, favorece a obtenção deste com características similares às do material natural.

Algumas pesquisas procuram otimizar as características dos agregados reciclados de concreto a partir da incorporação de finos reativos e não reativos, com o objetivo de envolver a superfície desse material com um cimento ou uma adição que preencha seus vazios e refine seus poros, como as pesquisas desenvolvidas por Tam e Tam (2008) e Tam, Gao e Tam (2005). Younis e Pilakoutas (2013) avaliaram o efeito das fibras e dos fíleres reativos e não reativos como mecanismo de tratamento superficial do agregado reciclado. Os resultados alcançados foram bastante satisfatórios para as propriedades analisadas.

Nessa vertente da melhoria do desempenho do concreto com agregado reciclado, acredita-se que resultados satisfatórios possam ser atingidos relacionando-se, entre outros fatores, a sistematização de sua produção. Ao executar concretos com resíduos de construção deve-se levar em conta suas peculiaridades, visto que são materiais heterogêneos, porosos e de baixa resistência ao desgaste, que variam a cada lote coletado. Além disso, os concretos com resíduos apresentam peculiaridades em virtude de suas condições de mistura, concreto de origem e outros.

Nesse sentido, o presente trabalho tem por objetivo colaborar com o estudo do processo de misturas em concretos com agregados graúdos reciclados de concreto, mediante a análise da influência das metodologias propostas para ordem de mistura (tradicional e modificada) no desempenho do concreto. Como objetivo específico analisar-se-á o efeito do tipo de misturador no desempenho do material, a fim de averiguar se os equipamentos utilizados nesta pesquisa foram adequados para a homogeneização desse tipo de concreto especial.

\section{Materiais e métodos}

O programa experimental tem por objetivo contribuir para o estudo do processo de mistura de concretos com agregados graúdos reciclados de concreto, com vistas a alcançar a otimização do processo. Para tal são avaliados os efeitos da ordem de mistura e do tipo de misturador no desempenho do concreto, a partir da análise da composição 
granulométrica, do módulo de finura e da resistência à compressão axial na idade de 28 dias.

\section{Materiais}

Os materiais utilizados nesta pesquisa foram o cimento CPV ARI, com resistência média aos 28 dias de $50 \mathrm{MPa}$, o agregado miúdo natural de origem quartzosa, a água proveniente da rede de abastecimento público e o agregado graúdo reciclado de concreto, que foi utilizado em substituição total ao agregado graúdo natural.

Os resíduos de concreto foram produzidos em laboratório a partir da cominuição de corpos de prova (CPS) de resistências médias de $30 \mathrm{MPa}$ na idade de 28 dias. Estes CPS foram confeccionados exclusivamente para esse fim, no intuito de fixar a origem dos resíduos. A fragmentação foi realizada em britadores do tipo mandíbulas, e a separação por frações granulométricas ocorreu a partir do peneiramento mecânico. Os finos $(<0,075 \mathrm{~mm})$ existentes na superfície dos agregados graúdos reciclados de concreto foram eliminados por meio de um processo lavagem, e os materiais passantes na peneira \#4,8 $\mathrm{mm}$ foram armazenados para pesquisas futuras.

Com relação à composição granulométrica foi estabelecido, com base em Cordeiro (2013), que o agregado graúdo reciclado seria composto de materiais passantes na peneira de \#25,0 $\mathrm{mm}$ e retidos na peneira $\# 6,3 \mathrm{~mm}$. As faixas adotadas nesta pesquisa foram \#19,0,\#12,5, \#9,5 e \#6,3 mm; a distribuição uniforme pelo número de peneiras levou a uma proporção de $25 \%$ de material retido em cada fração, e esta foi mantida fixa em todas as misturas.

Os ensaios de caracterização realizados nos agregados miúdos naturais foram: composição granulométrica (ABNT, 2003), massa específica (ABNT, 2009) e massa unitária (ABNT, 2006). Por meio desses ensaios foi obtido o resultado de 2,21 para o módulo de finura, enquadrando esse material na zona utilizável do limite inferior. Com relação à massa específica e à massa unitária, os valores encontrados foram respectivamente $2,62 \mathrm{~g} / \mathrm{cm}^{3} \mathrm{e}$ $1,57 \mathrm{~g} / \mathrm{cm}^{3}$.

Para determinação da massa específica e absorção de água dos agregados graúdos reciclados se adotou a metodologia proposta por Leite (2001) e Leite et al. (2011) respectivamente. A respeito da determinação da massa unitária foram seguidas as recomendações estabelecidas pela NBR NM 45 (ABNT, 2003). Os resultados obtidos foram de 2,73 $\mathrm{g} / \mathrm{cm}^{3}$ para massa específica, $5,6 \%$ para a absorção de água do agregado reciclado e $1,30 \mathrm{~g} / \mathrm{cm}^{3}$ para massa unitária. Atribuem-se essas características à escolha dos resíduos de origem e à metodologia de ensaio adotada.

\section{Parâmetros de misturas}

Para a produção do concreto foram estipulados como parâmetros fixos o tipo de resíduo, o tempo de mistura e o abatimento. A escolha pelo resíduo de concreto está relacionada às características físicas do material, como absorção de água reduzida, se comparado com um resíduo cerâmico, e massa específica acima da média de um material reciclado (CABRAL, 2007). O tempo total de mistura foi mantido constante em 3 min e $22 \mathrm{~s}$, determinado por meio de testes prévios realizados em laboratórios que apontaram ser esse o período mais adequado para homogeneizar os materiais e garantir a absorção de água do agregado graúdo reciclado nos dois equipamentos. A respeito do abatimento, a medida de $100 \pm 20 \mathrm{~mm}$ é uma característica do projeto do qual esta pesquisa faz parte.

Como fatores controláveis têm-se o equipamento de mistura (misturador de eixo vertical e betoneira de eixo inclinado) e a ordem de mistura dos materiais (tradicional e modificada), a partir dos quais se avaliou o efeito no desempenho do material reciclado. Assim, definiu-se se são adequados para a homogeneização desse tipo de concreto especial. Com relação às características dos equipamentos utilizados na produção de concretos com resíduos, optou-se por analisar dois equipamentos: um misturador de eixo vertical (Figura 1a) com tambor de 1801 e rotação de $24 \mathrm{rpm}$, capacidade de mistura de 1201 e potência de $1 \mathrm{CV}$, e uma betoneira de eixo inclinado (Figura 1b), com tambor de $1201 \mathrm{e}$ rotação de $28 \mathrm{rpm}$, capacidade de mistura de $801 \mathrm{e}$ potência de $1 / 2 \mathrm{CV}$.

A discussão que se tem a respeito dos processos de misturas de concretos com agregados reciclados consiste no fato de que as metodologias propostas, apesar de eficientes, demandam maior tempo e energia, o que inviabiliza sua operação (YOUNIS; PILAKOUTAS, 2013). Dessa maneira, optou-se por avaliar, para os dois equipamentos, duas sequências de misturas distintas (tradicional e modificada), com o mínimo de intervenção, e analisar sua eficiência para a situação mais crítica, que seria uma mistura com $100 \%$ de agregado graúdo reciclado, incorporado sob a condição seco ao ar, sem utilizar aditivos e adições. Cada sequência de mistura apresentava uma repetição, de modo a permitir mensurar a repetibilidade dos resultados. 
Figura 1 - Equipamentos utilizados na pesquisa: (a) misturador eixo vertical e (b) betoneira eixo inclinado

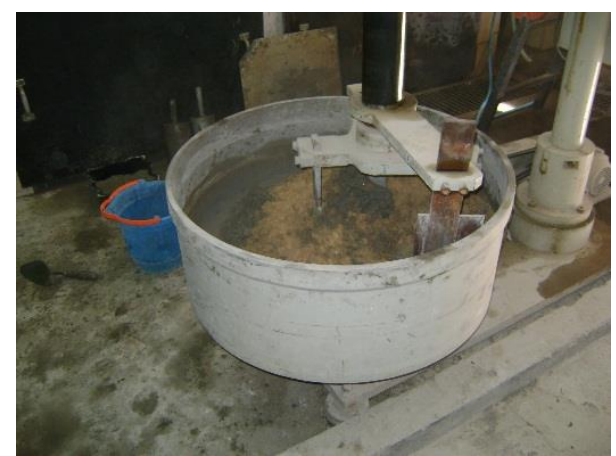

(a)

O desempenho das misturas foi analisado a partir de variáveis de respostas, a saber: o módulo de finura e a resistência à compressão axial. Pelo primeiro parâmetro buscou-se identificar as alterações granulométricas decorrentes da fragmentação dos agregados graúdos reciclados durante a mistura. Sendo assim, para cada equipamento foram feitas quatro misturas (duas para ordem tradicional e duas para ordem modificada), e ao final de cada uma delas se realizava uma lavagem em peneira com aberturas de $2,4 \mathrm{~mm}$, a fim de coletar a fração graúda do material. Em seguida, preparava-se o material segundo as recomendações estabelecidas pela NBR NM 248 (ABNT, 2003). Somente ao final desse processo era determinado o módulo de finura do agregado graúdo reciclado.

A resistência à compressão axial foi o parâmetro pelo qual se avaliou o desempenho mecânico do concreto com agregado reciclado após as misturas. Foram moldados 7 corpos de prova cilíndricos de dimensões 100x200 mm para cada combinação, seguindo a prescrição da NBR 5738 (ABNT, 2003). Aos 28 dias de idade esses exemplares foram ensaiados e seus resultados tratados estatisticamente.

\section{Dosagem da mistura}

Com o estudo de dosagem realizado pelo método IPT/Epusp (HELENE; TERZIAN, 1993) foi possível determinar o proporcionamento ótimo de materiais para uma resistência à compressão axial média de $30 \mathrm{MPa}$ na idade de 28 dias. A escolha por essa faixa de resistência foi estipulada com base na pesquisa de Cordeiro (2013), que constatou que o novo concreto deve preferencialmente apresentar valor de resistência à compressão axial menor ou igual ao do novo compósito, a fim evitar o aumento do consumo de cimento e a consequente elevação de custo. Na Tabela 1 encontram-se os consumos de materiais obtidos na dosagem.

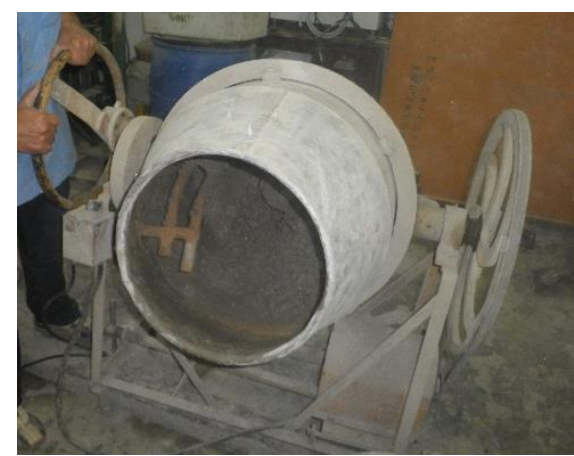

(b)

\section{Produção do concreto}

Conforme descrito anteriormente, a produção do concreto foi executada em misturador de eixo vertical e em betoneira de eixo inclinado. Nas duas seções a seguir são apresentadas as misturas realizadas na pesquisa.

\section{Sequência de mistura tradicional}

A Figura 2 mostra a representação da sequência de mistura denominada como tradicional. Na primeira etapa são incorporados o agregado reciclado e parte da água; em seguida são adicionados o cimento e a água; por fim, é colocada a areia e o restante da água.

Nota-se que esse processo apresenta três etapas de misturas. A primeira visa umidificar o agregado graúdo reciclado. A segunda objetiva tratar a superfície do agregado com o cimento, tal qual a proposta de Tam e Tam (2008), além de garantir que o agregado reciclado absorva a água da mistura. Já a terceira, na qual é adicionado o restante dos materiais necessários para a produção do concreto, visa homogeneizar a mistura até atingir a consistência desejada, de $100 \pm 20 \mathrm{~mm}$.

\section{Sequência de mistura modificada}

Percebeu-se que o misturador de eixo vertical, em função de sua potência, poderia promover desagregação do agregado reciclado durante o atrito das partículas. Tentando minimizar esse problema, optou-se por avaliar outro processo de mistura, no qual a primeira etapa seria direcionada para a produção da argamassa, com o intuito de amortecer o impacto do agregado reciclado com a betoneira e com os grãos durante a mistura. A Figura 3 mostra a sequência da mistura modificada. 
Tabela 1 - Consumos de materiais em massa

\begin{tabular}{l|c|c|c|c|c}
\hline \multirow{2}{*}{$\boldsymbol{a}$} & $\mathbf{a} / \mathbf{c}$ & $\mathbf{m}$ & $\mathbf{a}$ & \multirow{2}{*}{$\mathbf{C} \mathbf{c}\left(\mathbf{k g} / \mathbf{m}^{\mathbf{3}}\right)$} & \multirow{2}{*}{$\mathbf{C a}\left(\mathbf{k g} / \mathbf{m}^{\mathbf{3}}\right)$} \\
\cline { 3 - 5 } & & 4,71 & 2,20 & 2,51 & 370,91 \\
\hline Nota: Legenda: \\
a - porcentagem de argamassa seca; \\
a/c - relação água-cimento; \\
m - relação agregados-cimento; \\
a - relação agregado miúdo-cimento (kg/kg); \\
p - relação agregado graúdo-cimento (kg/kg); \\
Cc - consumo de cimento por metro cúbico de concreto; e \\
Ca - consumo de água por metro cúbico de concreto.
\end{tabular}

Figura 2 - Processo de mistura tradicional

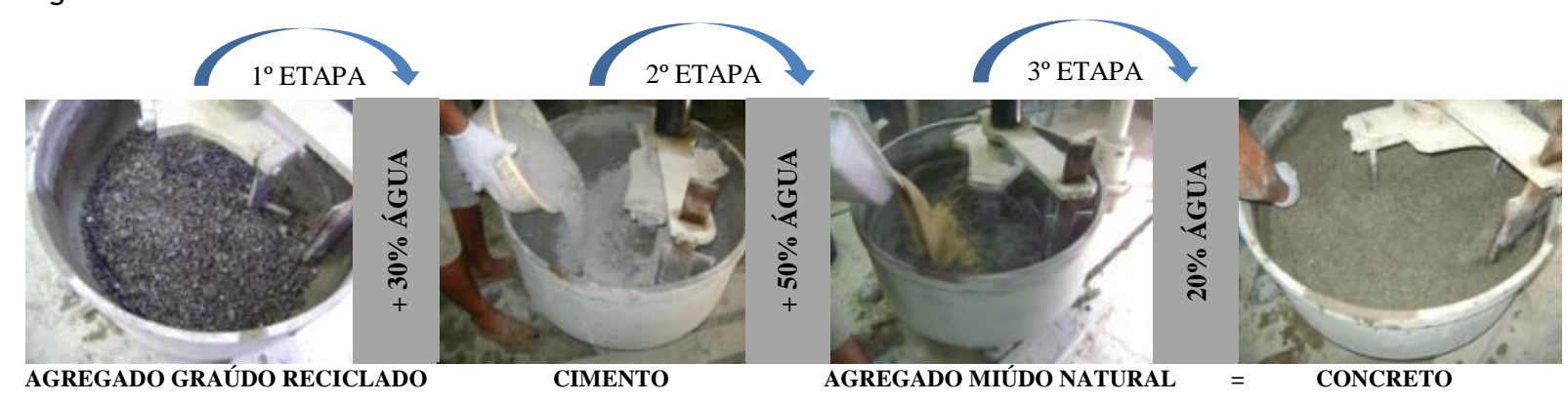

Figura 3 - Processo de mistura modificado

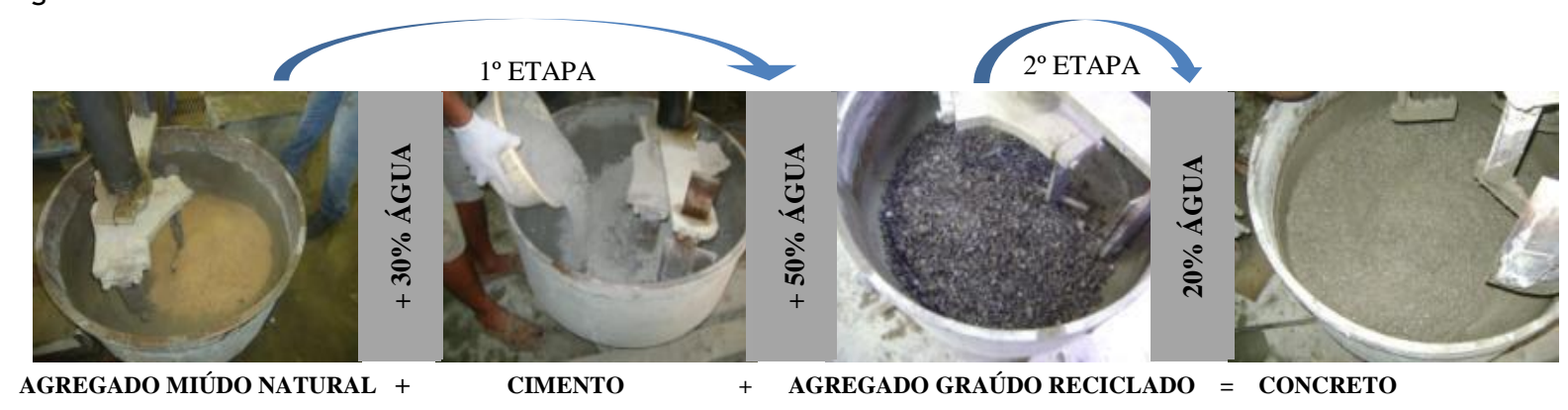

Ao final de cada sequência de misturas foram moldados corpos de prova, os quais foram armazenados em câmara úmida até a data de ensaio. Vale ressaltar que todas as sequências foram realizadas tanto no misturador de eixo vertical quanto na betoneira de eixo inclinado.

Aos 28 dias os corpos de prova foram submetidos ao ensaio de resistência à compressão axial a fim de avaliar a eficiência dos processos de misturas.

\section{Homogeneização em betoneiras de eixo inclinado}

Durante a pesquisa foi observado que os concretos homogeneizados em betoneiras de eixo inclinado apresentavam resultados de resistência à compressão axial com coeficiente de variação acima do limite aceitável. Devido a essa ocorrência decidiu-se investigar o comportamento granulométrico do agregado reciclado de concreto nesse equipamento. Dessa forma, ao final de cada sequência de mistura foram coletadas amostras em quatro pontos do equipamento, conforme mostra a Figura 4. Posteriormente foi realizado o ensaio de módulo de finura a fim de avaliar alterações granulométricas.

\section{Apresentação e análise dos resultados}

\section{Composição granulométrica e módulo de finura}

Os resultados mostram que nas misturas realizadas em misturador de eixo vertical houve a quebra dos grãos, o que promove redução nos valores de módulo de finura. Esse comportamento é atribuído à energia de mistura, que ocasiona a desagregação das partículas mais porosas e promove a geração de materiais finos. Com relação às misturas realizadas 
em betoneira de eixo inclinado, o módulo permaneceu inalterado. As Figuras 5 e 6 apresentam as curvas granulométricas, da porcentagem retida e retida acumulada desses materiais após as misturas.

Figura 4 - Representação esquemática dos pontos de coleta de concreto

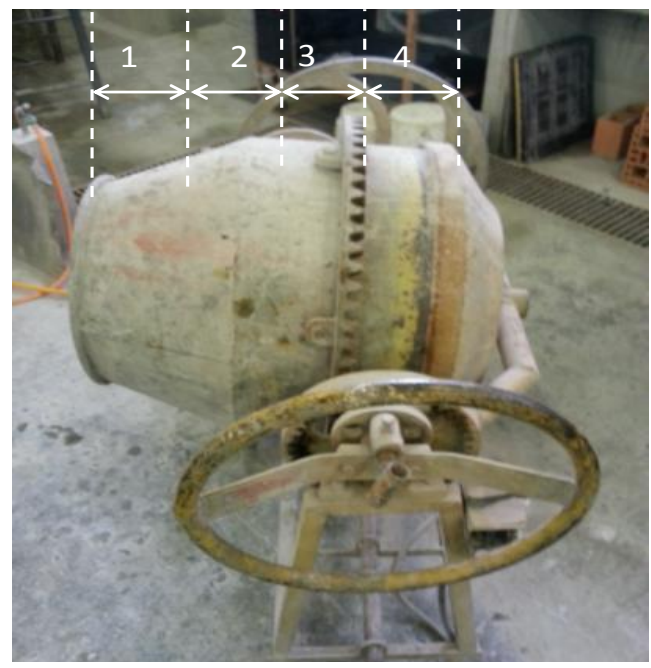

Figura 5- Curva granulométrica do misturador de eixo vertical: (a) gráfico discreto e (b) gráfico acumulado

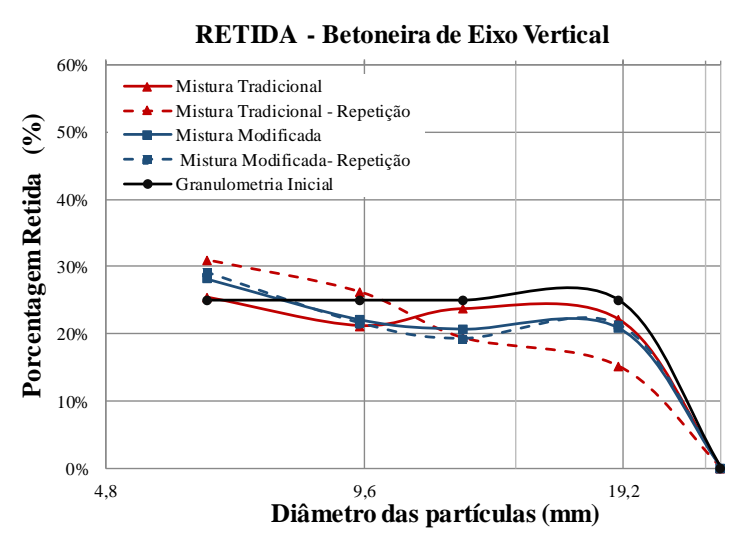

(b)

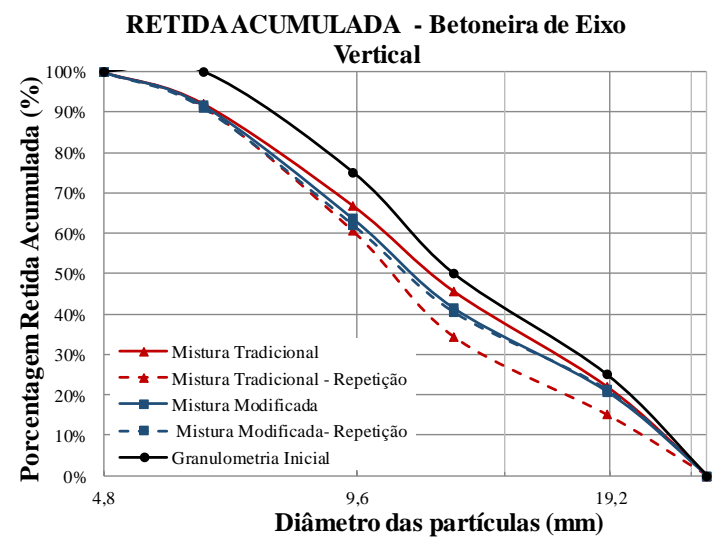

(a)

Figura 6 - Curva granulométrica do misturador de eixo inclinado: (a) gráfico discreto e (b) gráfico acumulado

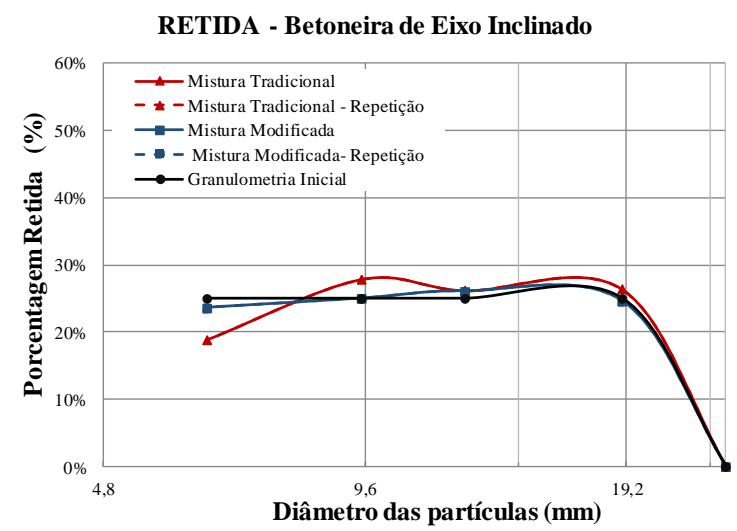

(a)

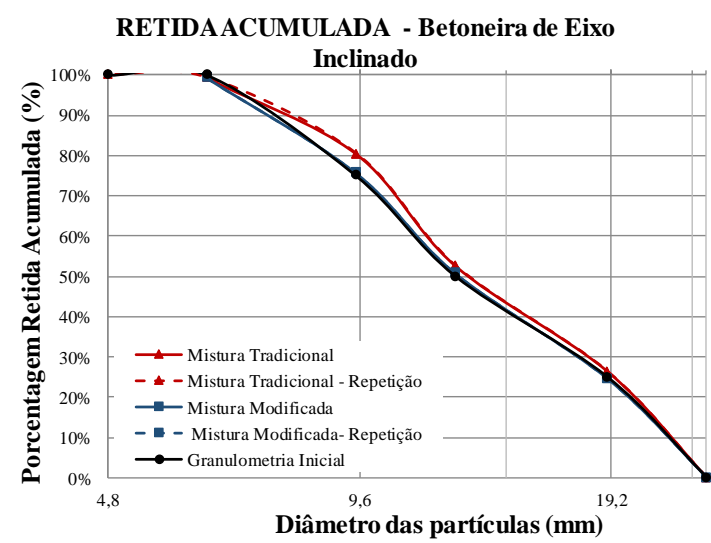

(b) 
As curvas discretas mostram que ocorreu desagregação de partículas nas misturas realizadas em misturador de eixo vertical. Para a betoneira de eixo inclinado, a granulometria permaneceu praticamente inalterada, tanto para a ordem de mistura tradicional quanto para a ordem de mistura modificada, e suas repetições. Contudo, os produtos desta betoneira apresentaram elevado coeficiente de variação. Esse fato foi atribuído a falhas na homogeneização, pois, dependendo do ponto onde era realizada a coleta, se obtinha um material com granulometria distinta, conforme mostrado nas Figuras 7 e 8 .
Para as duas condições de mistura os produtos coletados no ponto 4 apresentaram-se mais finos que os demais. Esse comportamento foi atribuído às características do misturador, o qual não se mostrou adequado para a homogeneização desse tipo de material, porque, mesmo com algumas intervenções nos procedimentos das misturas, foram necessárias intervenções para a separação dos conglomerados que se depositavam no misturador. Os materiais finos, que ficavam em sua maioria acomodados no fundo do equipamento e interferiam na homogeneidade do concreto, foram retirados para o prosseguimento da mistura.

Figura 7 - Curva granulométrica da mistura tradicional - betoneira de eixo inclinado

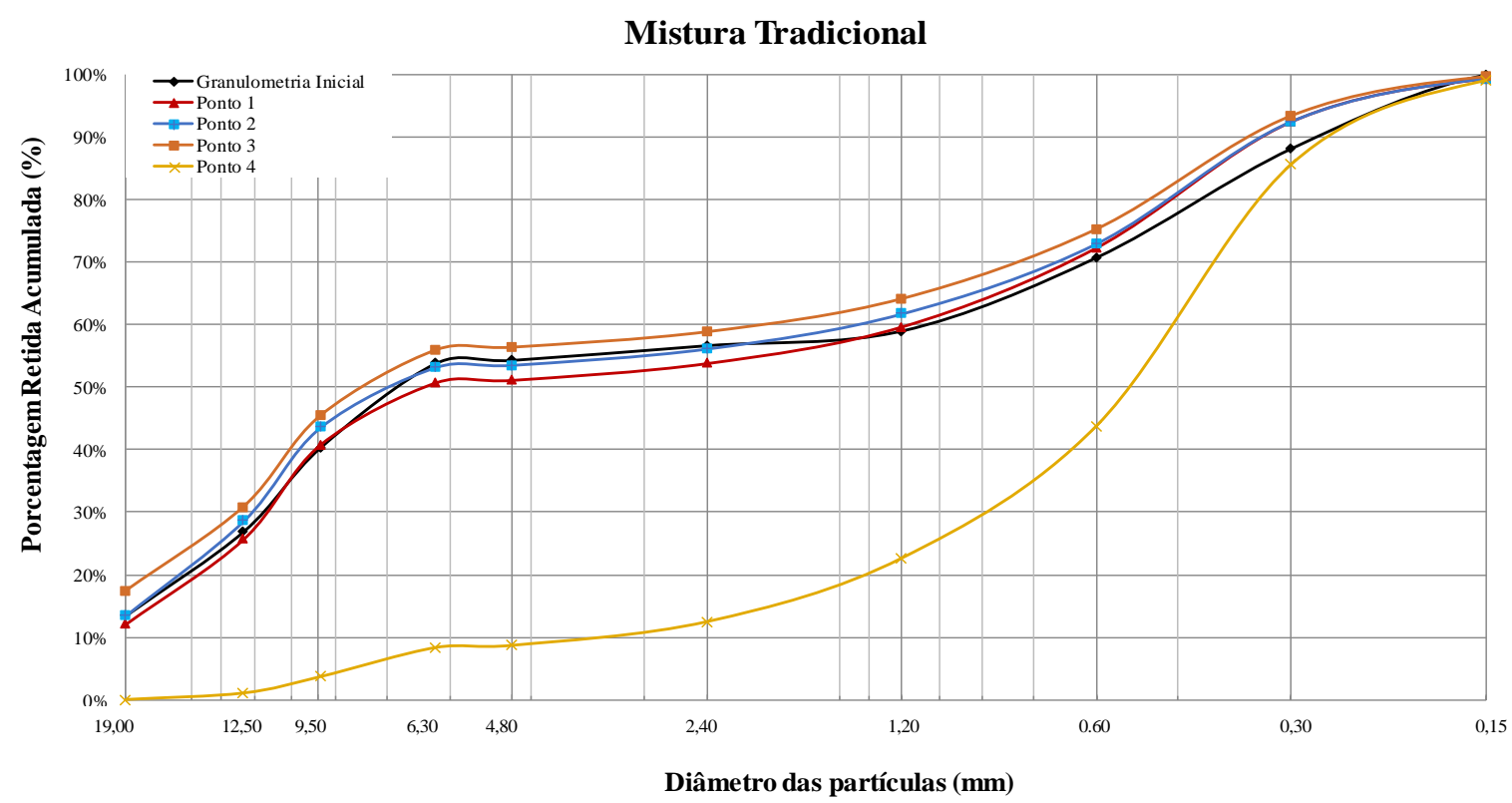

Figura 8 - Curva granulométrica da mistura modificada - betoneira de eixo inclinado

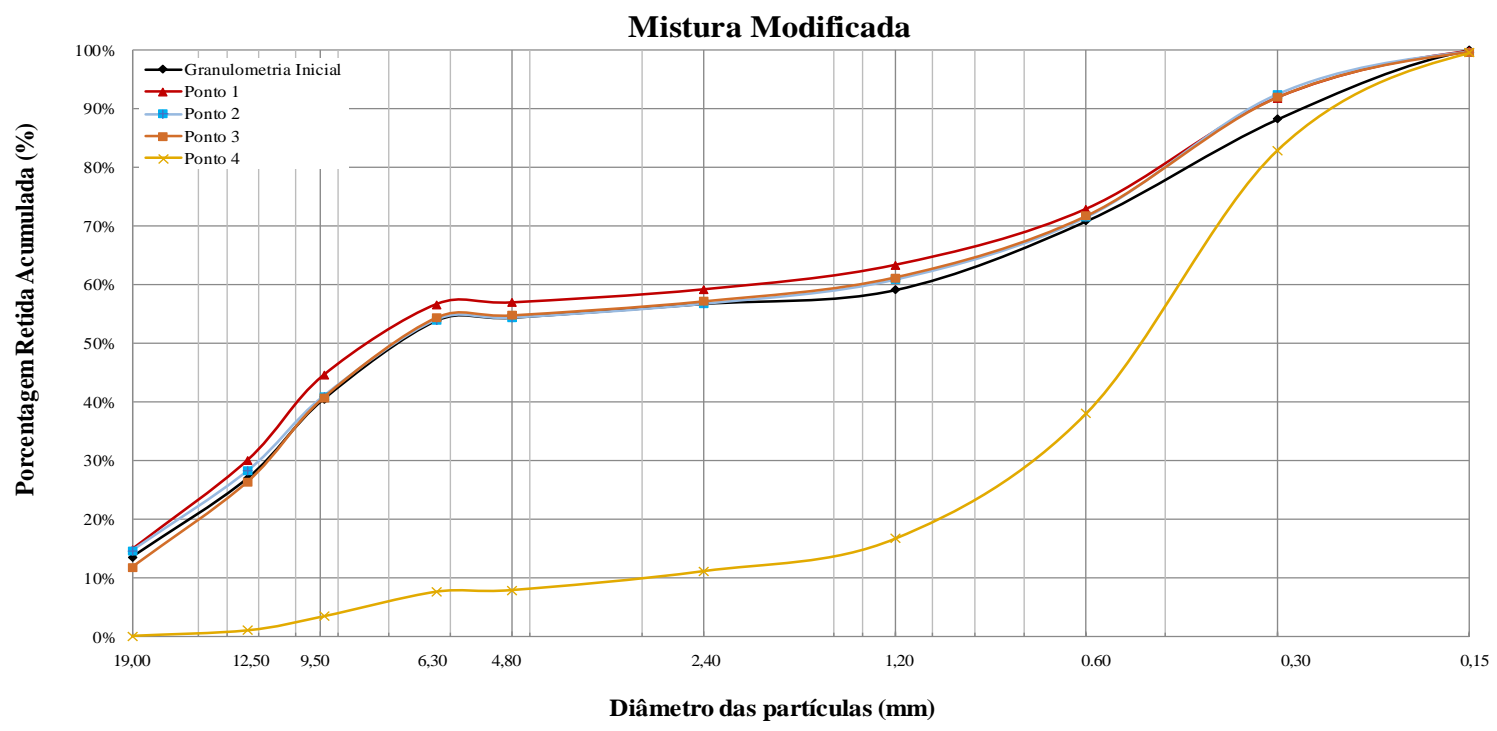


Com relação ao efeito do misturador no concreto, têm-se na Figura 9 os valores dos módulos de finura, antes e após a mistura, evidenciando que a betoneira de eixo vertical promove desgaste maior no agregado reciclado que o misturador de eixo inclinado, gerando mais finos, diferentemente do eixo inclinado, que não sofreu alteração quando comparado com a granulometria inicial.

\section{Resistência à compressão axial}

Os resultados de resistência à compressão, na idade de 28 dias, encontram-se na Tabela 2; anexos, estão todos os resultados obtidos.

As misturas produzidas em misturador de eixo vertical apresentaram resultados superiores do ponto de vista de resistência mecânica que as produzidas em betoneira de eixo inclinado. A diferença entre os resultados é de aproximadamente
$10 \%$. Com relação à variabilidade destes, vê-se que os concretos produzidos em betoneiras de eixo inclinado apresentaram maior coeficiente de variação.

Os resultados mostram que não existe diferença significativa entre as duas ordens de mistura e que as duas metodologias foram satisfatórias para alcançar a resistência preestabelecida. Com relação ao efeito dos equipamentos, percebe-se uma diferença significativa entre eles: o misturador de eixo vertical foi mais eficiente do ponto de vista de resistência mecânica em comparação com a betoneira de eixo inclinado. Essas misturas, além de apresentarem valor baixo de coeficiente de variação, promoveram um incremento de resistências. Tal comportamento foi atribuído às características do equipamento (capacidade de mistura e potência), que favoreceram a homogeneização.

Figura 9 - Valores de módulo de finura dos agregados graúdos antes e após a mistura

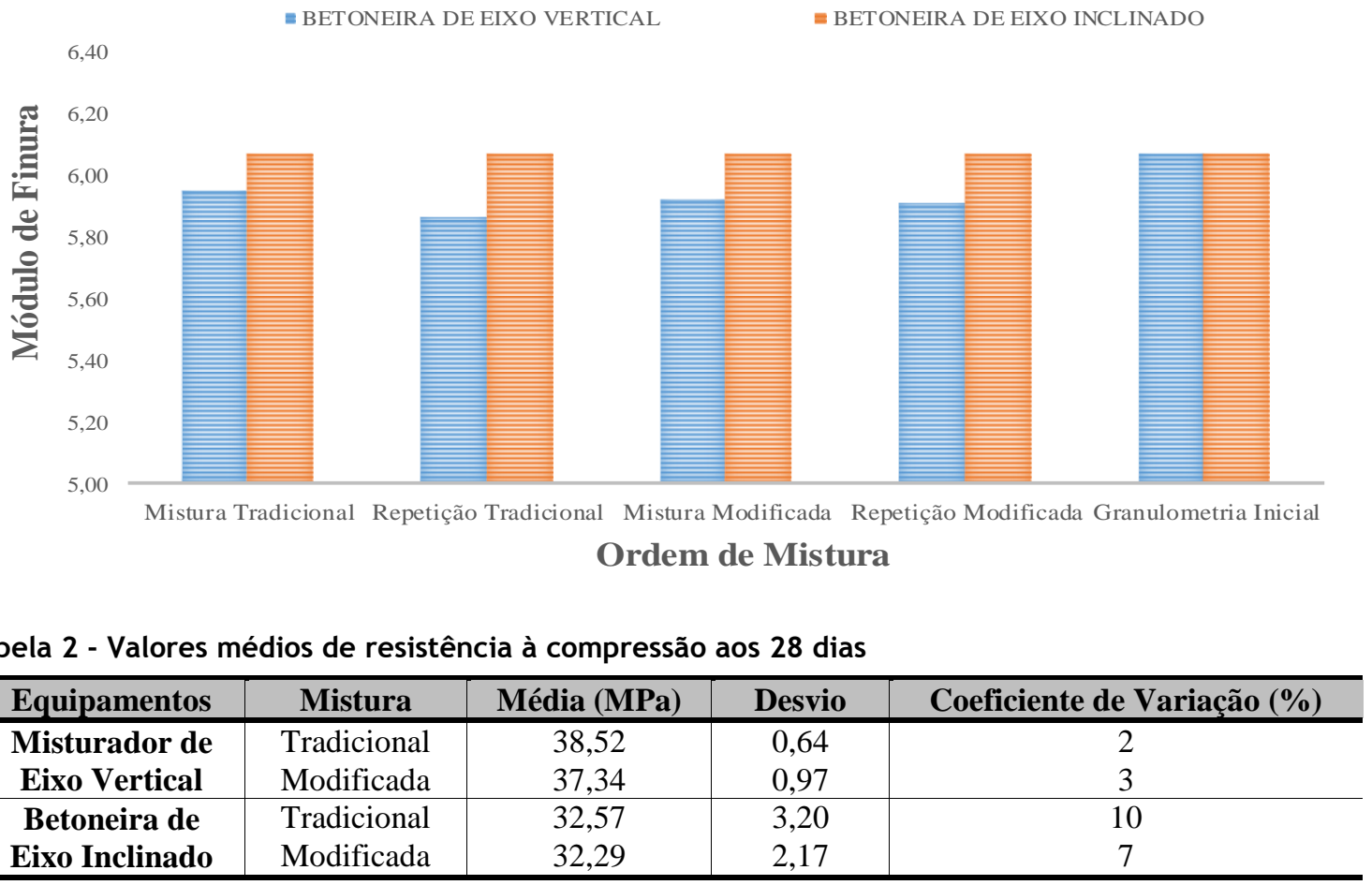

Tabela 3 - Análise de variância da resistência à compressão aos 28 dias

\begin{tabular}{c|c|c|c|c|c}
\hline & SQ & GL & MQ & F & p \\
\hline Equipamentos & 143,27 & 1 & 143,27 & 21,343 & 0,000100 \\
Ordem de Mistura & 1,15 & 1 & 1,15 & 0,172 & 0,682290 \\
Erro & 167,82 & 25 & 6,71 & & \\
\hline
\end{tabular}

Nota: Legenda:

SQ: soma quadrada;

$\mathrm{GL}$ : grau de liberdade;

MQ: média quadrada;

F: valor calculado de Fisher; e

p: nível de significância. 


\section{Conclusões}

Diante dos resultados conclui-se que os dois processos de misturas analisados foram eficientes para a produção do concreto. Em ambos foi possível alcançar a resistência à compressão axial de projeto.

Com relação ao efeito do tipo de equipamento no concreto, tem-se uma diferença significativa entre os resultados de resistência à compressão. As misturas produzidas em misturador de eixo vertical apresentaram resultados de resistência superiores aos produzidos em betoneiras de eixo inclinado; além disso, na betoneira de eixo inclinado a variabilidade dos resultados foi maior que o esperado. Esse comportamento foi atribuído à variação existente ao longo da betoneira, que não foi capaz de homogeneizar de forma eficiente os materiais, deixando que os finos se depositassem no fundo do equipamento. Acredita-se que essa deficiência na mistura seja responsável pela variabilidade dos resultados.

Por todas as condições apresentadas nesta pesquisa, visando a um melhor entendimento do tema, conclui-se que o misturador de eixo vertical se mostrou mais indicado para a produção de concretos com baixa variabilidade e que os processos de misturas em duas e três etapas favorecem o desempenho mecânico do concreto.

\section{Referências}

ANGULO, S. C. Caracterização de Agregados de Resíduos de Construção e Demolição Reciclados e a Influência de Suas Características no Comportamento de Concretos. São Paulo, 2005. Tese (Doutorado em Engenharia) - Escola Politécnica, Universidade de São Paulo, São Paulo, 2005.

ASSOCIAÇÃO BRASILEIRA DAS EMPRESAS DE LIMPEZA PÚBLICA E RESÍDUOS

ESPECIAIS. Panorama dos Resíduos Sólidos no Brasil. 2011. Disponível em:

$<$ http://www.abrelpe.org.br/Panorama/panorama20 11.pdf>. Acesso em: 15 nov. 2016.

\section{ASSOCIAÇÃO BRASILEIRA DE NORMAS} TÉCNICAS. NBR NM 248: agregados: determinação da composição granulométrica. Rio de Janeiro, 2003.

ASSOCIAÇÃO BRASILEIRA DE NORMAS TÉCNICAS. NBR NM 45: agregados: determinação da massa unitária e do volume de vazios. Rio de Janeiro, 2006.
ASSOCIAÇÃO BRASILEIRA DE NORMAS TÉCNICAS. NBR N5738: concreto: procedimento para moldagem e cura de corpos-de-prova. Rio de Janeiro, 2003.

\section{ASSOCIAÇÃO BRASILEIRA DE NORMAS}

TÉCNICAS. NBR NM 52 : agregado miúdo: determinação da massa específica e massa específica aparente. Rio de Janeiro, 2009.

BRITO FILHO, J. Cidade versus Entulho. In: SEMINÁRIO DO DESENVOLVIMENTO SUSTENTÁVEL E A RECICLAGEM NA CONSTRUÇÃO CIVIL, São Paulo, 1999. Anais... São Paulo, 1999.

\section{BUTTLER, A. Concreto Com Agregados}

Graúdos Reciclados de Concreto: influência da idade de reciclagem nas propriedades dos agregados e concretos reciclados. São Carlos, 2003. Dissertação (Mestrado em Engenharia de Estruturas) - Escola de Engenharia de São Carlos, Universidade de São Paulo, São Carlos, 2003.

CABRAL, A. E. B. Modelagem das Propriedades Mecânicas e de Durabilidade de Concretos Produzidos Com Agregados Reciclados, Considerando-se a Variabilidade da Composiçao do RCD. São Carlos, 2007. Tese (Doutorado em Ciências da Engenharia Ambiental) - Escola de Engenharia de São Carlos, Universidade de São Paulo, São Carlos, 2007.

CORDEIRO, L. N. Análise dos Parâmetros Principais Que Regem a Variabilidade de Concretos Produzidos Com Agregados Graúdos Reciclados de Concreto. Porto Alegre, 2013. Tese (Doutorado em Engenharia) - Programa de PósGraduação em Engenharia Civil, Universidade Federal do Rio Grande do Sul, Porto Alegre, 2013.

GOMES, P. C. C. et al. Comminution and Sizing Processes of Concrete Block Waste as Recycled Aggregates. Waste Management, v. 45, p. 171$179,2015$.

HELENE, P.; TERZIAN, P. R. L. Manual de Dosagem e Controle do Concreto. São Paulo: Pini, 1993.

JACOBI, P. R.; BESEN, G. R. Gestão de Resíduos Sólidos em São Paulo: desafios da sustentabilidade. Estudos Avançados, v. 25, n. 71, p. 135-158, 2011.

KATZ, A. Properties of Concrete Made With Recycled Aggregate From Partially Hydrated Old Concrete. Cement and Concrete Research, v. 33, n. 5, p. 703-711, 2003. 
LEITE, M. B. Avaliação das Propriedades Mecânicas de Concretos Produzidos Com Agregados Reciclados de Resíduo de Construção e demolição. Porto Alegre, 2001. Tese (Doutorado em Engenharia Civil) - Programa de Pós- Graduação em Engenharia Civil,

Universidade Federal do Rio Grande do Sul, Porto Alegre, 2001.

LEITE, M. B. et al. Proposta de Adaptação do Procedimento Proposto Por Leite ( 2001 ) Para Determinação da Absorção de Agregados Reciclados de Resíduo de Construção Demolição. In: CONGRESSO INTERNACIONAL SOBRE PATOLOGIA E REABILITAÇÃO DE ESTRUTURAS, 7. Fortaleza, 2011. Anais... Fortaleza, 2011.

LOVATO, P. S. Verificação dos Parâmetros de Controle de Agregados Reciclados de Resíduos de Construção e Demolição Para Utilização em Concreto. Porto Alegre, 2007. Dissertação (Mestrado em Engenharia Civil) - Programa de Pós-Graduação em Engenharia Civil, Universidade Federal do Rio Grande do Sul, Porto Alegre, 2007.

MOHAMMAD, A. R. et al. Effect of Replacing Natural Coarse Aggregate by Brick Aggregate on the Properties of Concrete. Dhaka University of Engineering \& Technology Journal, v. 1, n. 3, jun. 2012.

MÜLLER, A.; LINSZ, E. Processing of Concrete With High Performance Sonic Impulses. In: INTERNATIONAL RILEM CONF ON THE USE OF RECYCLED MATERIALS IN BUILDING AND STRUCTURES, 11, 2004. Proceedings... 2004.
RAO, A.; JHA, K. N.; MISRA, S. Use of Aggregates From Recycled Construction and Demolition Waste in Concrete. Resources, Conservation and Recycling, v. 50, n. 1, p. 7181, 2007.

TAM, V. W. Y.; GAO, X. F.; TAM, C. M. Microstructural Analysis of Recycled Aggregate Concrete Produced From Two-Stage Mixing Approach. Cement and Concrete Research, v. 35, p. 1195-1203, 2005.

TAM, V. W. Y.; TAM, C. M. Diversifying TwoStage Mixing Approach (TSMA) For Recycled Aggregate Concrete: TSMAs and TSMAsc. Construction and Building Materials, v. 22, n. 10, p. 2068-2077, 2008.

ULSEN, C. Caracterização e Separabilidade de Agregados Miúdos Produzidos a Partir de Resíduos de Construção e Demolição. São Paulo, 2011. Tese (Doutorado em Engenharia Civil) Programa de Pós-Graduação em Engenharia, Escola Politécnica, Universidade de São Paulo, São Paulo, 2011.

YOUNIS, K. H.; PILAKOUTAS, K. Strength Prediction Model and Methods for Improving Recycled Aggregate Concrete. Construction and Building Materials, v. 49, p. 688-701, 2013. 


\section{ANEXO - Resultados de Resistência à Compressão aos 28 dias (MPa)}

\begin{tabular}{|c|c|c|}
\hline Equipamento & Mistura & Fcj (MPa) \\
\hline \multirow{14}{*}{ Misturador de Eixo Vertical } & \multirow{7}{*}{ Ordem Tradicional } & 38,54 \\
\hline & & 37,62 \\
\hline & & 37,87 \\
\hline & & 38,69 \\
\hline & & 38,51 \\
\hline & & 38,82 \\
\hline & & 39,58 \\
\hline & \multirow{7}{*}{ Ordem Modificada } & 36,41 \\
\hline & & 37,46 \\
\hline & & 35,90 \\
\hline & & 38,39 \\
\hline & & 37,19 \\
\hline & & 38,57 \\
\hline & & 37,44 \\
\hline \multirow{14}{*}{ Betoneira de Eixo Inclinado } & \multirow{7}{*}{ Ordem Tradicional } & 28,55 \\
\hline & & 29,99 \\
\hline & & 30,62 \\
\hline & & 35,05 \\
\hline & & 31,35 \\
\hline & & 35,60 \\
\hline & & 36,82 \\
\hline & \multirow{7}{*}{ Ordem Modificada } & 34,11 \\
\hline & & 34,08 \\
\hline & & 31,69 \\
\hline & & 30,24 \\
\hline & & 30,93 \\
\hline & & 29,71 \\
\hline & & 35,25 \\
\hline
\end{tabular}

Nota: a fim de avaliar se os dados seguiam uma distribuição normal, foi realizado o teste de normalidade Shapiro-Wilk, pelo qual se pode afirmar, com nível de significância de $5 \%$, que a amostra provém de uma população normal, o que permitiu a realização da ANOVA.

Luciana de Nazaré Pinheiro Cordeiro

Faculdade de Engenharia Civil | Universidade Federal do Pará | Rua Augusto Corrêa, 937, Guamá | Belém - PA - Brasil | CEP 66075-110 | Tel.: (91) 3201-7254 | E-mail: lucianapc@ufpa.br

Angela Borges Masuero

Departamento de Engenharia Civil, Escola de Engenharia | Universidade Federal do Rio Grande do Sul | Av. Osvaldo Aranha, $99,3^{\circ}$ andar, Farroupilha | Porto Alegre - RS - Brasil | CEP 90035-190 | Tel.: (51) 316-3321 | E-mail: angela.masuero@ufrgs.br

\section{Denise Carpena Coitinho Dal Molin}

Departamento de Engenharia Civil, Escola de Engenharia | Universidade Federal do Rio Grande do Sul | Tel.: (51) 3308-4054 |

E-mail: dmolin@ufrgs.br

\section{Paulo Sérgio Lima Souza}

Departamento de Construção Civil, Centro Tecnológico | Universidade Federal do Pará | Tel.: (91) 3201-7917 | E-mail: paseliso@ufpa.br

Isaura Nazaré Lobato Paes

Faculdade de Engenharia Civil | Universidade Federal do Pará | Tel.: (91) 3201-7254 | E-mail: isaurapaes@ufpa.br

Revista Ambiente Construído

Associação Nacional de Tecnologia do Ambiente Construído

Av. Osvaldo Aranha, $99-3^{\circ}$ andar, Centro

Porto Alegre - RS - Brasil

CEP $90035-190$

Telefone: +55 (51) 3308-4084

Fax: +55 (51) 3308-4054

www.seer.ufrgs.br/ambienteconstruido

E-mail: ambienteconstruido@ufrgs.br 